\title{
AS INTERSEÇÕES DO TEMPO NOS ROMANCES ANGUSTIAE JEANNETTE DE AMÉLIA BEVILÁQUA
}

\author{
INTERSECTIONS OF TIME IN THE NOVELS ANGÚSTIA AND JEANNETTE DE AMÉLIA BEVILÁOUA
}

\section{RESUMO}

As obras de autoria feminina na sociedade brasileira do século XIX e limiar do século XX deu-se marcada pelo sistema patriarcalista, resultando na exclusão de muitas escritoras do cânone literário. Mesmo que muitas tenham tido uma produção literária significativa, para os padrões da época, não receberam por parte da crítica o tratamento merecido, como Amélia Beviláqua. Mesmo com uma obra composta por romances, poesias, contos e ensaios, o silêncio em torno dela ainda persiste, razão pela qual objetivamos, discorrer sobre algumas de suas obras, como Angústia e Jeannette. No romance Angústia, publicado em 1913, observamos que a escritora esteve sempre acima dos padrões convencionais aos que se considerava uma boa formação para moças. Já em Jeannette, suas preocupações acerca do destino da mulher repercutem igualmente em seus textos literários. Ao trazer a cena da historiografia literária Amélia Beviláqua e obras, esperamos contribuir para a inserção dos estudos sobre a escritora.

Palavras-chave: Amélia. Beviláqua. Literatura feminina. Cânone.

\begin{abstract}
The works of female authorship in nineteenth-century and at the threshold of twentieth century Brazilian literature, were marked by the patriarchal system. This has resulted in the exclusion of many writers from the literary canon. Even though many had a significant literary production if we take into account the standards of that period of time, they did not receive the critical attention they deserved. Thus, we bring Amélia Beviláqua to this scenario. Her work was composed of several novels, poetry, short stories and essays, but the silence on her production persists, which is why we present this article to discuss some of her works: Angústia and Jeannette. In Amelia Beviláqua's novel Angústia, published in 1913, we observed that the writer was always above conventional standards, taken as appropiated social models for girls. In Jeannette, her concerns about women's fate also echo with her literary texts. In bringing the scene of Brazilian literary historiography as a background to approach the writer Amélia Beviláqua and her Works, we intend to contribute to the develpment of these sudies on the author's work.
\end{abstract}

Keywords: Amelia Beviláqua.Feminine Literature. Canon.

Algemira de Macedo Mendes

Universidade Estadual do Piauí (UESPI).E-mail: algemiramendes95@gmail.com 
A inserção de obras de autoria feminina na sociedade brasileira do século XIX, e limiar do século XX deu-se, de certa forma, marcada pelo sistema patriarcalista, resultando na exclusão de muitas escritoras do cânone literário. Mesmo que muitas tenham tido uma produção literária significativa para os padrões da época, não receberam por parte da crítica o tratamento merecido.

Para ilustrar o dito acima, tem-se nas obras Angústia, da escritora Amélia Beviláqua, publicada em 1913, e Jeanete, publicada em 1993 um exemplo. Na primeira, percebe-se que a escritora esteve sempre acima dos padrões convencionais ao que se considerava uma boa formação para moças. Suas preocupações acerca do destino da mulher repercutem igualmente em seus textos literários. O romance Angústia é, sob este aspecto, desconcertante. Publicado no mesmo ano de Correio da roça, de Júlia Lopes de Almeida, o livro enfoca um tema mais arrojado que o dos romances de Júlia, em geral versando sobre o drama da mulher desprotegida, isto é, sem pai ou marido, que precisa fazer frente às necessidades da família. No romance de Amélia, no entanto, há radicalidade, pois, vivendo com um marido que não a compreende e suspeitando de sua lealdade, a protagonista rompe definitivamente a relação conjugal e escolhe seu próprio caminho.

As obras de Amélia Beviláqua, abordadas nesse texto, foram produzidas no interstício do XIX e XX; por isso, problematizam questões tanto tratadas nas tendências literárias do final do século XIX, como referentes aos auspícios da nova era. Essas, fogem da visão determinista, reservada à mulher na sociedade patriarcal, como fizeram Júlia Lopes e Lucia Miguel Pereira com relação à emancipação da mulher. Não há um engajamento com o chamado romance regionalista e social das décadas do século XX, mas avançam em muitas questões, sobretudo, na luta pela igualdade dos direitos entre homens e mulheres, bem como oportunizam ao seu leitor ou leitora o contato com o afã da modernidade da Belle Époque carioca, em torno dos cafés, salões, livrarias e nos passeios à rua do Ouvidor, assim como fizeram João do Rio, Luis Edmundo e Lima Barreto. A esse respeito, salientamos aqui o pensamento de Mônica Pimenta Veloso (1996), a qual aponta que, em fins do século XIX, a configuração do campo intelectual carioca poderia ser assim delineada: o grupo da Garnier, que se polariza em torno da figura de Machado de Assis; os nefelibatas, liderados por Cruz e Sousa; e os grupos boêmios, reunidos sob a liderança de Paula Nei. Pertenciam a esses grupos figuras como José do Patrocínio, Olavo Bilac, dentre outros.

Cotejando a obra da escritora Amélia, percebe-se que, desde os artigos publicados na revista Lyrio, ela já defende os direitos da mulher, como educação superior e voto feminino. ${ }^{1}$ Em seus romances iniciais, como Através da Vida, publicado em 1906, e Vesta, 1908, suas personagens, ainda que tênues, já se mostram insatisfeitas com as imposições a que são sujeitas, enquanto filhas e esposas.

Em Angústia, a escritora dá um avanço. A imagem da mulher, mais do que em Jeanete quer se fazer independente e é indiferente aos olhares punitivos da sociedade.

1 Lyrio, Recife, ano 1, n. 2, p. 10-12, 1902. 
No romance Angústia, a autora materializa sua posição, a partir da voz que narra a história. Uma senhora passeia sozinha de bonde ou caminha pelo centro da cidade, em que outras mulheres seguem acompanhadas por "seus maridos, pais ou amantes". Integrado ao contexto do progresso carioca, naquele momento especial para a capital do país (há inclusive referências à abertura da Exposição Nacional de 1908), ${ }^{2}$ o argumento do livro põe em cena o casal Artur e Teresa. Ele, "um insubmisso antifeminista", ela, uma linda e inteligente mulher. Enciumado, Artur vê em Teresa uma mulher egoísta e presunçosa, porque a encontra sempre absorta em suas leituras. A narradora localiza as causas da insatisfação de Artur, talvez motivo de desconstrução da imagem da esposa feita por ele:

\begin{abstract}
Nãolhe nego talento ecultura; quem éque não sabe, porém, quanto a mulher é inepta! Jamais terá capacidade para penetrar o segredo das ciências. [...] Onde é que estão os livros de mulheres em que se encontram estrutura, concepção e valores, como num livro de homem? As que escrevem são confusas, incorretas, não têm estilo próprio nem forma. De seus trabalhos não se tiram conclusões senão as que vêm, diretamente, do coração. Passando do terreno sentimental, nada mais conseguem. Como, pois, poderei julgar minha mulher?! Será uma egoísta, presunçosa, ou simplesmente, da numerosa família das histéricas? ( BEVILAQUA,1913:79-81)
\end{abstract}

As desavenças do casal culminam num dia em que Teresa, chegando da missa, senta-se apressada para o almoço já posto. $\mathrm{O}$ marido, ao perguntar sobre onde ela esteve, recebe uma vaga resposta. Insiste, e a esposa argumenta: - "O senhor nunca me diz onde vai."

O marido, não admitindo ser tratado daquela maneira - afinal ao homem pertencia o espaço público, logo, uma mulher não teria o direito de sair à rua sem ser acompanhada -, não suportando o inusitado da situação, negando-se a lhe dar explicações e ainda querendo tratar a questão de igual para igual, ao dizer que ele não lhe diz aonde vai, propõe-lhe o divórcio, aceito imediatamente.

A autora, dentre outras questões extra-textuais, apresenta duas não muito comum nas narrativas escrita por mulheres. A primeira, o divórcio ser tratado por uma mulher, quando sua legalização ocorreu 64 anos após a publicação da obra. A segunda, o adultério feminino, até então considerado crime pelas Ordenações do Reino que vigoram no Brasil colonial, permanecendo até o Império, ${ }^{3}$ fundamentada no Livro V das Ordenações Filipinas, ${ }^{4}$ que nos regeu de 1603 a 1830; nos Códigos: Criminal;

2 A Exposição Nacional de 1908, realizada para comemorar o centenário da Abertura dos Portos às Nações Amigas. Ver: <http://www.museuhistoriconacional.com.br>. Acessado em: 25 set. 2006.

3 Até 1512, estiveram em vigor Ordenações Afonsinas, 1569, as Manuelinas, substituídas estas últimas, em 12 de fevereiro de 1569, pelo Código de D. Sebastião, que perdurou até 1603. Ver: GARCIA, Basileu. Instituições de direito penal. 4. ed. rev. atual. São Paulo: Max Limonad, 1971.

4 O Livro V das Ordenações do Rei Felipe II (compiladas, por Felipe I em 11 de janeiro de 1603, o nosso primeiro Código Penal). Ver: Ordenações Filipinas. Lisboa: FCG, 1985. V. Ordenações e leis do Reino de Portugal. Coimbra: Na Real Imprensa da Universidade de Coimbra, 1824. T. III. 
Processo de 1832, de 1890, Penal da Armada, promulgado em 1930, reformulado, em 12 de abril de 1940 (nesta última reformulação é que se extingue o artigo que considerava crime o adultério).

No Código Civil de 1916, adultério feminino constitui-se motivo de dissolução da sociedade conjugal. ${ }^{5}$ Clovis Bevilaqua, na defesa de seu projeto de Código Civil, discursava sobre a libertação da mulher de uma inferioridade que não mais se compadecia com a concepção atual da vida, retirou do projeto do Código a incapacidade expressa da mulher casada, justificando a manutenção da chefia da sociedade conjugal unicamente na necessidade de haver quem assumisse a direção de modo a harmonizar as relações da vida conjugal. Clóvis Bevilaqua não atribuía as razões da hierarquia e das restrições impostas à mulher à inferioridade física e mental, uma vez que homens e mulheres são dotados de capacidade equivalente. A razão era a diversidade de funções que os consortes eram chamados a exercer junto à sociedade e à família. ${ }^{6}$

A Comissão revisora do projeto de lei não aceitou a inovação e recusou-a, sem admitir discussão. O tão esperado Código Civil acabou confirmando a tendência conservadora e consagrou a superioridade do homem, dando o comando único da família ao marido, sendo a mulher casada marcada pela incapacidade jurídica relativa, equiparada aos índios, aos pródigos e aos menores de idade. Condição alterada no que se refere à capacidade civil das mulheres, a partir da revisão no Código Civil de 2002, que no artigo $5^{\circ}$, não traz diferenciação entre homens e mulheres.

Posto isto, pode-se se dizer que as representações femininas apresentadas em Angústia, são molduras das relações sociais, de uma sociedade patriarcal de então. Por outro lado, a não submissão da personagem às imposições do marido implica uma tomada de consciência dela, enquanto ser subjugado. Percebe-se que, à medida que ela começa a tomar contato com novas ideias, a instituição familiar começa a ser abalada e as mudanças comportamentais começam a surgir:

A mulher, que vive para o marido, não tem estas etiquetas.

Que sonhos não terá tido o Ramos com o simples pensamento de sentir, em redor do pescoço, aquelas mãos macias?

$[\ldots]$

Nunca me deixarei dominar por essa vilania; não quero é passar por imbecil; gosto de zelar o que é meu; seria uma abominação muito grande viver debaixo da tutela de um namorado de minha mulher, que se lembrasse de me suplantar.

Serei por ventura um covarde?

Hei de me deixar empolgar, por uma atriz, uma criatura inferior, que não poderá jamais me dar ventura, e que se diverte à custa de meus sofrimentos? Aquele sono sossegado me abala, cruelmente, os nervos. ( BEVILAQUA,1913:56-58)

$5<$ www6.senado.gov.br/sicon/ExecutaPesquisaBasica.action>. Acessado em: 28 set. 2006.

6 Ver artigo de Clóvis Beviláqua, "A mulher perante o Código Civil Brasileiro", publicado no Almanaque Brasileiro Garnier. Rio de Janeiro, ano 1, p. 225-227, 1903. 
Como se pode observar, a mulher não mais se satisfaz com os papéis domésticos impostos pela tradição patriarcal. Com isso, a autora busca mostrar, por meio dos seus escritos, os condicionamentos sociais impostos à mulher na época. $\mathrm{O}$ marido, que se sente desrespeitado por sua mulher, atribui o seu comportamento às leituras por ela feitas. O protagonista Arthur Lourenço considera Guy de Maupassant e Zola cânones do Naturalismo, como má influência para as mulheres. No entanto, ele exalta filósofos como Pascal, Arthur Schopenhauer. ${ }^{7}$

Percebe-se que a autora demonstra conhecimento sobre os teóricos que influenciaram o pensamento científico do século XIX e início do século XX, o que aparece explicitamente por meio da voz das personagens ou o leitor perspicaz filtra na leitura do texto. Muitas vezes, a voz do protagonista dramatiza o inconsciente coletivo da sociedade de então, como forma, quem sabe, de verbalizar também suas próprias angústias.

Jeanete, publicado em 1933, também configura-se como narrativa urbana. Pelo contexto, percebe-se que se trata de uma cidade com muitas características de província. Ademais, a narradora restringe quase todas as cenas da trama a espaços restritos. O espaço da protagonista homônima da obra limita-se, na maioria das vezes, ao espaço privado, o lar, de solteira que apresenta através de analepses, ou a casa onde vive após o casamento. As cenas externas são poucas, mas quando são evidenciadas no enredo dizem respeito geralmente ao esposo da Jeanete, Dr. Geleda. Com vista nisso, pode se adiantar que os lugares ocupados pelo homem e pela mulher ficam bem demarcados na obra em análise. A voz masculina se antecipa e sarcasticamente emite seus pareceres sobre o estatuto da mulher na sociedade, logo no início da trama.

Da mesma forma, a discussão sobre a condição da mulher desdobra-se no romance Jeannette, que, embora posterior, é menos arrojado que Angústia. O enredo, como o anterior, põe em cena um casal discutindo a pretexto de um tema já lançado em Angústia: o ciúme do marido. Amélia, uma vez mais, o trata como alguém que se considera esperto, mas Jeannette, a personagem-título, é muito mais. Visto pela narradora, o marido é descrito como um cínico:

Em plena lua-de-mel, reparou o Dr. Amaral Geleda, que a sua bela mulher andava envolvida em uma grande tristeza, e sorriu, maliciosamente. Sabia, muito bem, que eram os primeiros sintomas do ciúme. Pobres mulheres, [...] como são tolas! Suas amantes foram também assim. Nem uma razoável! E isso era de norte a sul! Que belo estudo, tradução livre de filosofia, onde encontrara a verdadeira profundeza de uma lógica inigualável, para escrever o seu primeiro livro sobre a originalidade feminina. ( BEVILAQUA1933:9-1)

7 Ver SCHOPENHAUER, Arthur. Aforismos para a sabedoria na vida. São Paulo: Melhoramentos, 1953. p. 232. <www6.senado.gov.br/sicon/ExecutaPesquisaBasica.action>. Acessado em: 28 set. 2006.

Ver artigo de Clóvis Beviláqua, "A mulher perante o Código Civil Brasileiro", publicado no Almanaque Brasileiro Garnier. Rio de Janeiro, ano 1, p. 225-227, 1903. 
No desenrolar das ações o protagonista confirma: São todas assim mesmo. [...] A mesma linha de demarcação; querem as pretensiosas o direito da igualdade... direitos individuais, constituir uma personalidade soberana, em tudo arranjar lugar superior... estadistas! ${ }^{8}$

Jeannette, por sua vez, pondera que, enlevada, a mulher acredita sempre no homem, e isso a desqualifica. Ambos vivem estremecidos, mas o marido insiste em que a esposa lhe conte os amores de sua juventude, quando ainda era descompromissada. Ela arquiteta, assim, uma vingança: narraria pequenas histórias para "vê-lo estonteado de ciúmes". O marido, perplexo com entrechos cada vez mais detalhados e comprometedores, observa: "E me parecia tão meiga e ingênua, quando somente vejo uma viciosa namoradeira de profissão!..." Instigada pelo marido, conta-lhe que se deixara beijar por um dos admiradores. Na verdade, diz ela prazerosamente, foram vários beijos, e correspondidos. Assombrado, ele insiste em saber o nome do homem, e ela, ousada, revela ter sido o irmão dele, morto havia dois anos. Finalmente, ele constata que a ama verdadeiramente, e ela, considerando-se vingada, reconcilia-se com o marido. Parece que o casal mede forças, e a esposa, mais astuta, sai vencedora.

As duas obras apresentam uma visão bastante cética do ponto de vista das personagens masculinas em relação ao amor e à mulher. A imagem que as personagens, Artur Lourenço e Amaral Geleda, fazem da mulher é comparada, muitas vezes, a imagens demoníacas. Pode-se fazer uma analogia com os romances realistas e naturalistas. Isto também remete as experiências vividas por outras mulheres no século XIX, que eram vítimas dos ciúmes doentios de seus maridos, fato constatado com frequência nas mulheres burguesas, pois as mulheres de classe baixa, segundo Mary del Priore, ${ }^{9}$ eram mais livres.

Nas duas obras, também a temática das relações humanas é tratada por meio de uma linguagem renovada, que recupera o ritmo da fala, descreve as agruras sofridas pelas personagens, da mesma forma que descreve os prazeres das coisas cotidianas, revigorando a palavra, de forma a torná-la mais flexível e sugestiva. Muitas vezes, também, as relações intersubjetivas entre homem/mulher são problematizadas e refletidas com os silêncios, as reticências e pontuação dos diálogos.

Com esses comentários sobre as temáticas feitas pela autora, percebe-se que ela foge da tradição do romance realista/naturalista do século XIX, e ainda presente no início do século XX, que, na sua grande maioria, punia o adultério feminino. Em Angústia, a discussão em torno do adultério tem como consequência somente a separação efetiva do casal: o marido abandona o lar e tenta reconstruir sua vida, não a mata, em nome da honra protegido pelo aparato das leis. Como, também, as confissões das aventuras amorosas da personagem Jeannete, ou mesmo o fato de um dos antigos namorados ser o irmão do esposo, não provocam a dissolução do casamento. Ao contrário, a vingança arquitetada por ela serve para reaproximá-los. Amélia acreditaria de fato que a mulher deveria fazer o mesmo jogo do homem? Ou, ao contrário, a trama

8 Id., ibid., p. 25-26.

9 PRIORE, Mary del. História das mulheres no Brasil. São Paulo: UNESP; Contexto, 1997. 
é tão precária só para que a narradora pudesse dizer o que pensa dos homens traidores e das mulheres vingativas? Ou antecipa a discussão das chamadas relações abertas?

\section{Referências}

BEVILAQUA, Amélia.(1913) Angustia. 1. ed. Paris: Ganier.

BEVILAQUA, Amélia. (1933). Jeannette. ed. Paris: Ganier.

BEVILAQUA, Amélia. (1906). Através da vida. 1. ed. Paris: Ganier.

BEVILÁQUA, Amélia. (1908). Vesta. 1. ed. Rio de Janeiro: Papelaria Americana.

GARCIA, Basileu. (1971) Instituições de direito penal. 4. ed. rev. atual. São Paulo: Max Limonad.

PRIORE, Mary del. (1997). História das mulheres no Brasil. São Paulo: UNESP; Contexto.

$<$ www6.senado.gov.br/sicon/Executa PesquisaBasica.action>. Acessado em: 28 set. 2006

SCHOPENHAUER, Arthur. (1953)Aforismos para a sabedoria na vida. São Paulo: Melhoramentos.

MENDES, Algemira de Macêdo. A imagem da mulher na obra de Amélia Beviláqua. Rio de Janeiro.: Caetés.

VELOSO, Mônica Pimenta. (1996) Cafés, revista, e salões: microcosmo intelectual e sociabilidade. In. Modernismo no Rio de Janeiro: turunas e Quixote. Rio de Janeiro: Fundação Getúlio Vargas. p. 35-70. 